or animal medicine will be sent to a research centre in Sweden for one year, while one Swedish research worker in the same range of disciplines will be supported at a research centre in the United Kingdom. Further information can be obtained from the Wellcome Trust, 52 Queen Anne Street, London, W.1.

\section{Postgraduate Course in Nutrition}

Tre latest development in the rapidly developing Department of Nutrition at Queen Elizabeth College, Campden Hill Road, London, W.8, is the introduction of a course leading to the University of London academic postgraduate diploma in nutrition. This one-year course, directed by Prof. John Yudkin, of Queen Elizabeth College, is meant chiefly for graduates in medicine, agriculture or veterinary science. It will give a comprehensive training in the various aspects of nutrition; it will deal not only with the physiology and biochemistry of nutrition, but also with the social and anthropological factors concerned with food habits, with the effects on nutritional value of modern methods in food producing and food processing, and with the economic and demographic aspects of food distribution. This course follows the introduction a few years ago, also at Queen Elizabeth Colleg, of courses leading to the degree of B.Sc. (Nutrition). People with this degree are now doing research in nutrition-some in industry and some in academic institutions-or teaching nutrition, or working in the developing countries. The new postgraduate course will provide a formal training for those medical men and others who, after graduating, find that they wish to make a career in the field of nutrition, in which there is important work waiting to be done both at home and overseas.

\section{University News:}

Birmingham

A. A. Walters, senior lecturer in the Department of Econometrics and Social Statistics in the University of Birmingham, has been appointed to the newly established chair of econometries and social statistic from January 1. Titles of reader have been conferred as follows: Dr. J. C. Bevington (chemistry of polymers); Dr. G. A. Gilbert (biophysical chemistry); Dr. J. Sheridan (physical chemistry). Appointments to lectureships are as follows: Dr. A. H. M. Hoare (pure mathematics); Dr. J. Lowe (nuclear physics); R. J. Sury (engineering production). J. P. Barton has been appointed to be Nuffield Research Fellow in the Department of Physics. Other Research Fellowships are: Dr. Luichie G. Kno-Petravic (nuclear physics); E. J. Hughes (physical metallurgy).

Bristol

Mr. J. R. Hugh Sumner has presented $£ 50,000$ to the University. This generous gift is intended to be applied specifically for the better equipment, improvement and maintenance of the new Rheumatism Wing of the Clinical Research Annexe to the Queen Elizabeth Hospital where the research work of the clinical departments of the University is carried out.

London

DR. C. W. Jones, reader in applied mathematics in the Imperial College of Science and Technology, has been appointed to the chair of mathematics applied to engineering tenable at that College.

The title of professor of mathematics has been conferred on Dr. W. B. Bonnor in respect of his post at Queen Elizabeth College.
The title of reader in chemical pathology has been conferred on Dr. P. G. Walker in respect of his post at the Institute of Orthopædics.

\section{The Night Sky in January}

New moon occurred on Jan. 6d. 12h. 36m. U.T. and full moon on Jan. 20d. $18 \mathrm{~h} .17 \mathrm{~m}$. The following conjunctions with the Moon take place: Jan. 16d. 17h., Aldebaran 0.6 ${ }^{\circ}$ S.; Jan. 23d. 04h., Regulus $0 \cdot 6^{\circ} \mathrm{S}$. In addition to these conjunctions with the Moon, Mercury is in conjunction with Jupiter on Jan. 16d. 17h., Mercury being $0.4^{\circ} \mathrm{S}$. Mercury is an evening star, visible later in the month low in the south-west after sunset. Venus, Mars, Jupiter and Saturn are all too close to the Sun for easy observation. Occultations of stars brighter than magnitude 6 are as follows, observations being made at Greenwich: Jan. 16d. 15h. 33.0m., $\alpha$ Tau. $(D)$; Jan. 16d. 16h. 16.6m., $\propto$ Tau. $(R)$; Jan. 17d. 03h. 14.3m., 318B. Tau. $(D)$; Jan. 17d. 17h. 31.7m., 120 Tau. $(D)$; Jan. 23d. 04h. 11.5m., $\alpha$ Leo. $(D)$; Jan. 23d. 05h. 18.7m., $\alpha$ Leo. $(R)$; Jan. 30d. 04h. 37.9m., $\gamma$ Lib. $(D)$; Jan. 30d. 05h. 43.7m., $\gamma$ Lib. $(R) ; D$ and $R$ refer to disappearance and reappearance, respectively. The Quadrantid meteors were active during January $3-4$, conditions being fairly favourable; the radiant is near R.A. 15 h. $28 \mathrm{~m}$., Dec. $+50^{\circ}$. The Earth was at perihelion on January 2, its distance from the Sun being $91 \cdot 3$ million miles.

\section{Announcements}

Mr. W. K. Brasher, secretary of the Institution of Electrical Engineers, has been elected a corresponding member of Den Norske Ingeniorforening (the Norwegian Institution of Engineers).

Mressrs. W. H. Freeman and Co., Ltd., Hyde House, West Central Street, London, W.C.1, announce that they hold reprints of articles appearing in The Scientific American. They can now supply from their London office more than 250 different articles (price 1s. 6d. each) which have appeared in that journal during the past ten years or so. A complete list of these reprints will be sent on request.

THE Plastics and Polymer Group of the Society of Chemical Industry has instituted an annual award of $£ 50$ for a paper on any aspect of the science of synthetic macromolecules. Further information can be obtained from the Plastics and Polymer Group Award, c/o Society of Chemical Industry, 14 Belgrave Square, London, S.W.I.

A Press course, organized by the Reactor School of the Atomic Energy Research Establishment, Harwell, is to be held at the School during February 7-8. Further information can be obtained from J. N. Hull, Reactor School, Atomic Energy Research Establishment, Harwell, Didcot, Berks.

A school of theoretical chemistry, organized by the Department of Physical Chemistry, Hebrew University of Jerusalem, is to be held in the Depart. ment during April 2-14. Further information can be obtained from the Department of Physical Chemistry, the Hebrew University of Jerusalem, Israel.

A counse of eight lectures on "The Application of Computers to Engineering Problems" has been arranged by the Borough Polytechnic, London. The lectures will be delivered on Wednesday evenings, beginning on January 17. Further information can be obtained from the Secretary, Borough Polytechnic, Borough Road, London, S.E.1. 